\title{
Study on Mesoscale Damage Evolution Characteristics of Irregular Sandstone Particles Based on Digital Images and Fractal Theory
}

\author{
Lujing Zheng, ${ }^{1,2}$ Lulin Zheng $\mathbb{D}^{1}{ }^{1}$ Yujun Zuo, ${ }^{1}$ Hao Liu, ${ }^{1,3,4}$ Bin Chen, ${ }^{1}$ Zhonghu Wu, ${ }^{5}$ \\ Wenjibin Sun, ${ }^{1}$ and Yingle Wang ${ }^{1}$ \\ ${ }^{1}$ College of Mining, Guizhou University, Guiyang 550025, China \\ ${ }^{2}$ Guizhou Jinfeng Mining Limited, Southwest of Guizhou, Guizhou 562204, China \\ ${ }^{3}$ College of Resource and Environmental Engineering, Guizhou University, Guiyang 550025, China \\ ${ }^{4}$ Department of Civil and Environmental Engineering, Technical University of Catalonia (UPC), 08034 Barcelona, Spain \\ ${ }^{5}$ College of Civil Engineering, Guizhou University, Guiyang 550025, China
}

Correspondence should be addressed to Lulin Zheng; zhenglulin1983@126.com

Received 30 July 2021; Accepted 13 November 2021; Published 27 November 2021

Academic Editor: Song Jiang

Copyright $\odot 2021$ Lujing Zheng et al. This is an open access article distributed under the Creative Commons Attribution License, which permits unrestricted use, distribution, and reproduction in any medium, provided the original work is properly cited.

\begin{abstract}
To study the mesoscale damage evolution law of irregular sandstone particles, based on RFPA2D and digital image processing technology, a real mesostructure numerical model of irregular sandstone particles is established to simulate the breakage process of particles, the effects of loading conditions and mesoscale heterogeneity on irregular sandstone particle damage are studied, and the calculation method of fractal dimension of irregular rock particles mesoscale fracture is proposed. The results show that the fracture damage degree $(\omega)$ and fractal dimension $(D)$ maximum values of the constrained particles are 0.733 and 1.466, respectively, and the unconstrained particles are 0.577 and 1.153, respectively. The final failure mode of constrained particles is more complicated than unconstrained particles, the damage is more serious, and the fracture is more complete. Thus, the larger values of $D$ yield a more complicated final failure mode of the particles. Consequently, with the larger $\omega$, the final damage is more serious, and the breakage effect is comparatively better. The study is of great significance for exploring the laws of rock particle breakage and energy consumption, rock breakage mechanism, and searching for efficient and energysaving rock-breaking methods.
\end{abstract}

\section{Introduction}

Crushing is the process of turning a large piece of material into a small piece of material under external force, which is widely used in the mineral industry. The crushing operation is the first step to reduce the particle size of the ore or to dissociate useful minerals from the monomer in the ore in the crushing process, which aims to reduce the particle size. So far, it is an urgent problem to understand the fracture process and damage mechanism of particles from the mechanical point of view [1]. Therefore, revealing the mechanism of particle breakage has practical engineering significance for seeking efficient and energy-saving rock breakage methods and guiding energy saving and consumption reduction in mines.
Evertsson's study shows that the breakage of brittle materials such as rock is a complicated process; revealing the breakage process of a single particle under load is an important step in understanding particle fragmentation [1]. The breakage of materials is traditionally considered to be a single-particle breakage without considering the confinement conditions; the breakage of materials can be determined by Griffith's theory of brittle fracture [2]. However, the breakage behavior of single particles under without confinement conditions is not the same as that under with confinement conditions; when stress is applied to confinement particles, the stress distribution on the surface will be more complicated. Therefore, it is necessary to accurately model the breakage condition of a single particle when studying the breakage behavior of the particles, which will be 
affected by multiple loads from adjacent particles [3]. Therefore, in the simulation of particle breakage, the confinement conditions should be considered to better understand the breakage process between particles. However, usually, the breakage behavior of rock particles is affected by their loading conditions, shape, and size [3]. Due to the complexity of the problem, there are many difficulties in analyzing the breakage process and damage evolution of rock particles. With the development of computer technology, numerical simulation methods seem to provide the possibility of revealing the mechanism of particle breakage [4]. Tang et al. developed the RFPA2D software based on the mesodamage mechanics theory, simulated the breakage process of rock particles under different loading conditions, and verified that RFPA2D is a suitable tool to study particle breakage [5]. Based on RFPA2D (dynamic version), Zuo et al. studied the breakage process of single-particle rock under impact load and discussed the crushing effect and energy consumption law of rock particles under different impact loads [6]. Zhou et al. developed a combined discretefinite element method to simulate the breakage behavior of single particles and verified the reliability of the method [7]. Based on the FDEM method, Wei et al. studied the fracture behavior of single-particle breaking under rotational point loading [8].

The above scholars have made a lot of achievements in revealing the mechanism of particle fragmentation, but these studies ignore the real mesostructure of rock particles. A rock's mechanical properties are closely related to its mesostructure such that the breakage processes and macroscopic mechanical properties are dependent on the mesoscale behavior and mesostructure of the materials. Therefore, the establishment of numerical models that can reflect the real mesostructure of rock particles is a strong guarantee for the numerical calculation to obtain reliable results, which is of great significance for revealing the breakage mechanism of rock particles. With the development of computer graphics hardware and image processing software, digital image processing (DIP) technology has been applied to the study of rock mechanics[9]. Liu et al. used digital image processing technology to characterize the mesouniformity of sandstone, established a numerical model considering the real mesostructure of sandstone, and analyzed its fracture process [10]. Liang et al. using a digital image and $3 \mathrm{D}$ reconstruction technology obtained the structural parameters, for example, the quantity of 3D voids, the degree of voids, the appropriation of voids along the height direction, and the coefficient of variation of the proportion of the coarse aggregate area [11]. Li et al. analyzed the fractal characteristics of coal by digital image processing technology and systematically studied the pores and cracks of coal under different pressures [12]. Yue et al. combined digital images and the finite element method (FEM) to study heterogeneous geotechnical materials. With this method, they were able to truly characterize the heterogeneous characteristics of porous materials and study their mechanical properties [13]. By combining digital image processing technology with the original RFPA2D numerical simulation system, $\mathrm{Yu}$ et al. established an RFPA2D-DIP numerical model based on the real mesostructure of rock and carried out numerical simulations of three kinds of conventional rock mechanics tests for rock specimens [14]. $\mathrm{Wu}$ et al. established a numerical model of shale mesoscale by combining digital images with finite element software and analyzed its fracture mode and fractal characteristics under uniaxial compression [15]. However, the above research results are based on the knowledge gained from the rule test pieces; few attempts have been made to study the breakage process in rock particles by establishing a numerical model based on the real mesostructure of irregular rock particles under different loading conditions.

Based on the above problems, this paper uses digital image processing technology to characterize the spatial distribution of minerals in irregular sandstone particles, so as to obtain the real mesostructure of the particles and map it to the finite element mesh, combined with RFPA2D-DIP software to establish a real mesostructure numerical model of irregular sandstone particles. The mesoscale breakage process of sandstone particles under different loading conditions is simulated, the effects of different loading conditions and mesononuniformity on breakage of irregular sandstone particles are studied, and the fractal characteristics, damage evolution, and acoustic emission distribution of breakage process of rock particles in numerical experiments are discussed.

\section{Background Theory}

2.1. DIP Technique. Digital image processing (DIP) is a new field that categorically studies and analyzes the theory, technology, and application of digital images. It widely involves transforming the required research objects into digital images and then carrying out sophisticated computer processing to enhance the quality of digital images and extracting the image information using computer-aided software to obtain useful research results about the subject of investigation. A pixel can be defined as the smallest element with an area formed when longitudinal and transverse scan lines intersect each other. A pixel normally consists of 0-255 values representing three primary color components, red $(R)$, green $(G)$, and blue (B). In order to explain the image information mathematically, three discrete functions are required, and hence each pixel becomes a function of red $(\mathrm{R})$, green $(\mathrm{G})$, and blue (B). The HSI space, which refers to hue, saturation, and intensity (brightness), is most related to our intuitive perception of color and it more naturally reflects the sensation of the color of human perception. The hue component refers to the names that we give to colors, red, green, yellow, orange, purple, and so on, and its values range from 0 to 360 that represent the dominant reflected wavelength of the color of the object under investigation. The saturation component $\mathrm{S}$ describes a color in terms of pale versus vivid with values 0 to 1 and is a representation of purity of color. The intensity component represents luminance and describes whether a color is light or dark. The HSI space is utilized because it provides a comparatively better understanding of colors. Based on variation in color and gray-scale value, the spatial distribution and geometrical 
shape of the mesocomponents of materials are determined by DIP technology. This technology is utilized to produce an enhanced image representing the nonuniformity of the material of rock by classification of segmentation thresholds based on color and brightness of different media inside the rock. A 2-dimensional CT slice is shown in Figure 1(b), which is obtained through high-resolution CT scanning of a sandstone sample at Tianjin Sanying Company. The digital image represents the true colors of the stone sample, that is, a 24-bit digital image of a sandstone stone sample with a joint filled with calcite. For the purpose of studying the evolution process of breakage and damage of irregular particles, irregular CT slices were obtained by performing image processing in Figures 1(b) and 1(c).

Since the color variation in the digital image is not very obvious, so the image was processed further to improve the appearance of the imagery to assist in visual interpretation and analysis. According to previous research, the I value in the HIS color space is selected as the image segmentation threshold $[10,14]$. The locality where the $\mathrm{AA}^{\prime}$ scan line moves through the imagery is shown in Figure 1(c), and alongside the scan line $\mathrm{AA}^{\prime}$, a graphical representation of the development in the value of $I$ is shown in Figure 1(d). A comparison between the medium through which the scan lines passed and the change of the curve was analyzed, and many tests were performed on ImageJ software to find a segmentation threshold that was 150. Consequently, the value of I can be categorized into two subsections 0 to 150 for sandstone and 150 to 255 for the calcite filled in the joint. Therefore, the internal medium of the sandstone is divided into two categories based on the variation in the I values. Figure $1(\mathrm{e})$ is a digital representation of the mesostructure image obtained by digital image processing. The geometrical and spatial distribution of the sandstone and calcite two of the sandstone sample can be clearly seen in the picture. Sandstone is represented with red, while calcite is represented with gray, respectively. It can be seen from Figure 1(e) that digital image processing technology can better characterize the heterogeneity of sandstone.

2.2. Representation of Damage on the Mesoscopic Scale via Constitutive Relationship. In RFPA2D, by assuming strain equivalence and based on the variation in elastic modulus, the damage variable is defined precisely [16]. A constitutive relationship after an external force causes damage to the sample material under investigation can be expressed as $[6,17,18]$

$$
E=(1-\omega) E 0,
$$

where $\omega$ is damage variable, $E_{0}$ represents the elastic modulus when the material is not damaged, $E$ represents the elastic modulus when the material is damaged.

The tensile strength of the sandstone is very less than its compressive strength, so we chose the Mohr-Coulomb failure/shear strength and maximum tensile stress as criteria for element failure [17]. And its mesodamage constitutive relationship is shown in Figure 2. Initially, the stress-strain curve is linear, so the damage would be none, $D=0$. When the mesoelement under uniaxial tension reaches the maximum tensile strain, brittle damage occurs. The primary failure mode of brittle rocks is tensile-induced failure $[19,20]$. As soon as the tensile stress approaches $f_{t}$ (tensile strength) of the element, damage takes place as per the main damage criteria. The function of tensile damage is expressed as [21]

$$
F^{-}(\sigma)=\sigma_{3}+f_{t}=0,
$$

where the principal stress vector is represented by $\sigma$. The third quadrant of Figure 3 illustrates that the constitutive relationship for the mesoscopic element under uniaxial tension can be expressed as $[9,18]$

$$
\omega= \begin{cases}0, & \varepsilon_{t 0} \leq \varepsilon<0, \\ 1-\frac{\lambda \varepsilon_{t 0}}{\varepsilon}, & \varepsilon_{t l} \leq \varepsilon<\varepsilon_{t 0}, \\ 1, & \varepsilon<\varepsilon_{t l} .\end{cases}
$$

where $\lambda$ represents the mesoscopic element's residual intensity coefficient, described as $\mathrm{f}_{\mathrm{tr}}=\lambda f_{t}$ (where mesoscopic element's uniaxial tensile strength is given by $f_{\mathrm{t}}$, whereas $f_{t r}$ is the residual strength at the element's initial tensile failure), and element's ultimate tensile strain is given by $\varepsilon_{t l}$. When the element's uniaxial tensile strain goes to ultimate tensile strain, then the element goes to tensile fracture state. $\eta$ is defined as the ultimate strain coefficient, specifically expressed by $\varepsilon_{t l}=\eta \varepsilon_{t 0} \cdot \varepsilon_{t 0}$ is tensile strain corresponding to elastic limit that can be named as tensile failure strain threshold, which is calculated as [17]

$$
\varepsilon_{t 0}=-\frac{f_{t}}{E_{o}}
$$

When a mesoscopic element is exposed to uniaxial compression, as illustrated in the first quadrant of Figure 2, the Mohr-Coulomb criteria for damage are used as the second criterion, which defines element damage under compressive or shear stress conditions [22]:

$$
F^{+}(\sigma)=\sigma_{1}-\sigma_{3} \frac{1+\sin \varphi}{1-\sin \varphi}-f_{c}=0,
$$

where friction angle is given by $\varphi$, principal stresses are given by $\sigma_{1}$ and $\sigma_{3}$, and uniaxial compressive strength is given by $f_{c}$. $\varepsilon$ element's damage variable under uniaxial compression may be given as $[23,24]$

$$
\omega= \begin{cases}0, & \varepsilon \leq \varepsilon_{t 0}, \\ 1-\frac{\lambda \varepsilon_{t 0}}{\varepsilon}, & \varepsilon \geq \varepsilon_{t 0},\end{cases}
$$

where the coefficient of residual strength is given by $\lambda$, described as $f_{t r} / f_{t}=f_{c r} / f_{c}=\lambda$, whereas at the elastic limit, compressive strain is given by $\varepsilon_{t 0}$ that can be determined as $[23,24]$ 


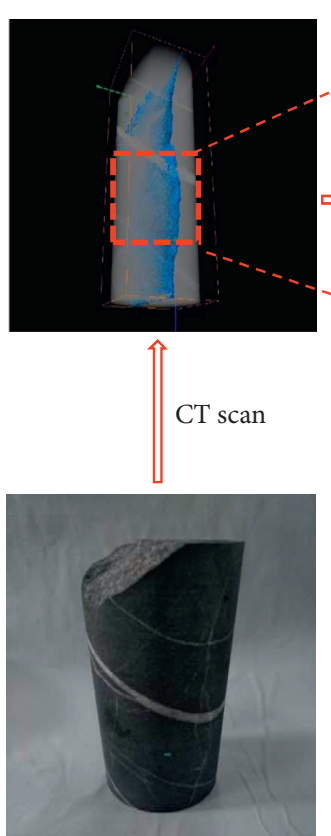

(a) Sandstone samples

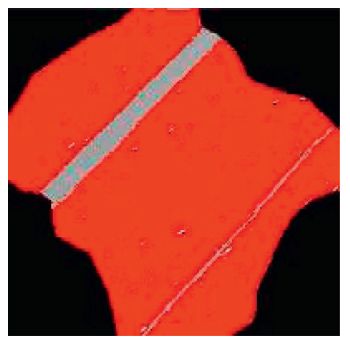

(e) Image resulting from thershold segmentation

calcite

sandstone

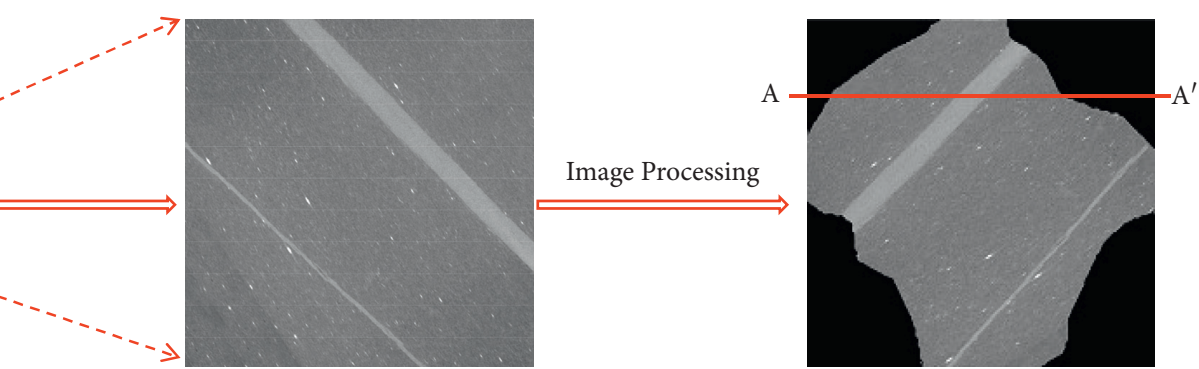

(b) Two-dimensional CT slice

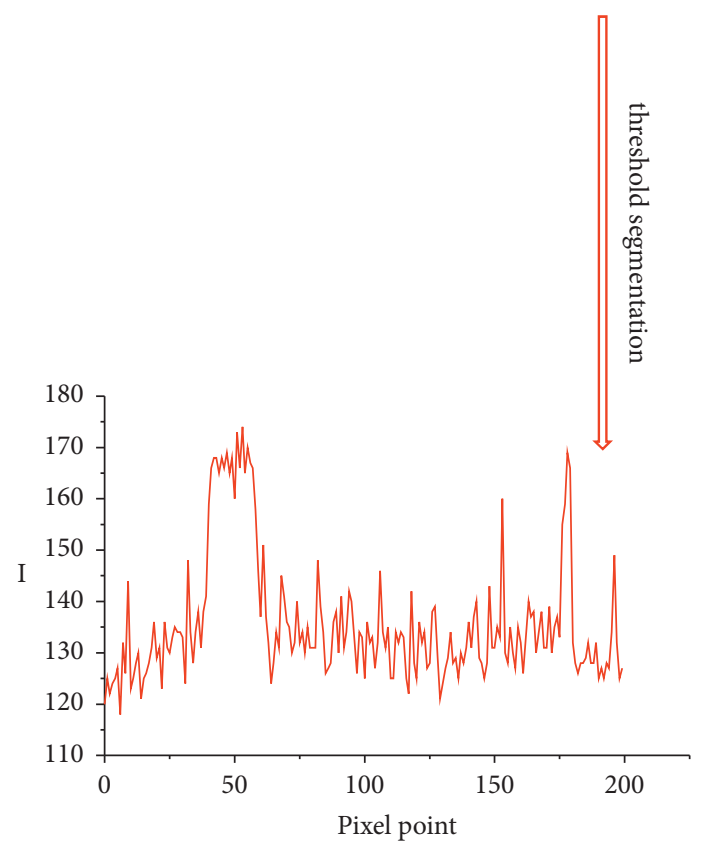

(d) Variation in the I value along scan line $\mathrm{AA}^{\prime}$

FIGURE 1: Irregular particle digital image processing process. (a) Sandstone samples. (b) Two-dimensional CT slice. (c) Irregular CT slice. (d) Variation in the $I$ value along scan line $\mathrm{AA}^{\prime}$. (e) Image resulting from threshold segmentation.

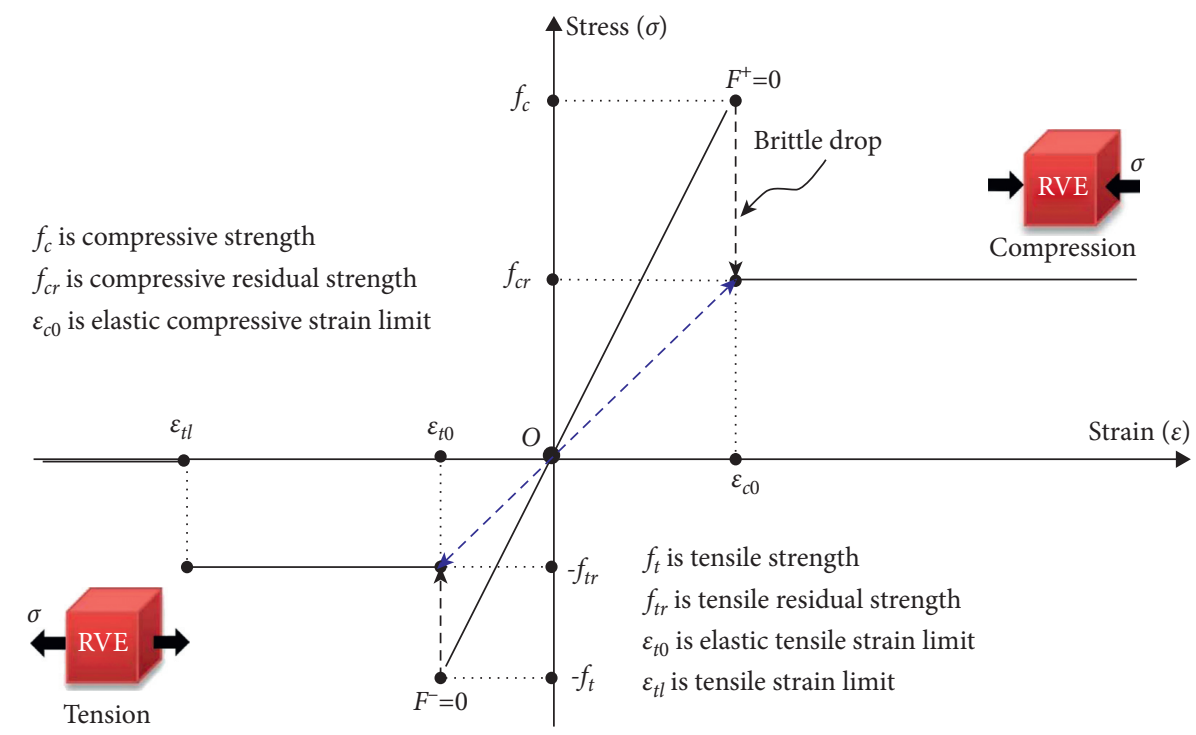

Figure 2: Constitutive relationship of mesoscale damage of element. 


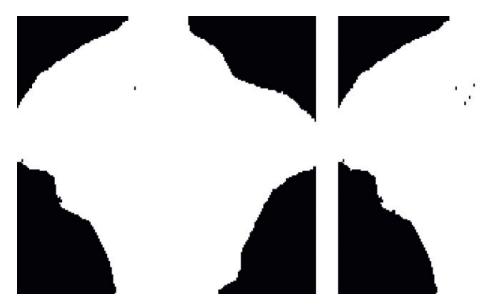

Step 42

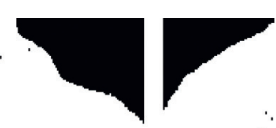

$\Delta$

Step 57 qr

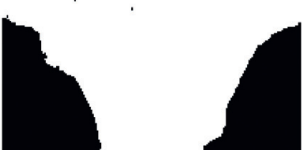

Step 72

(a)

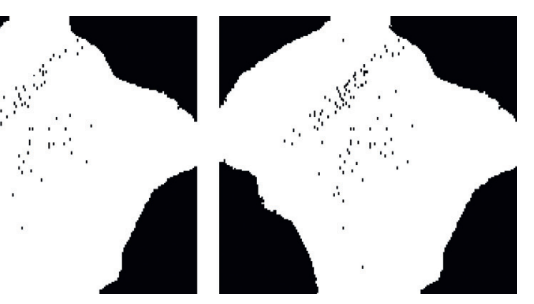

Step 101
Step 116

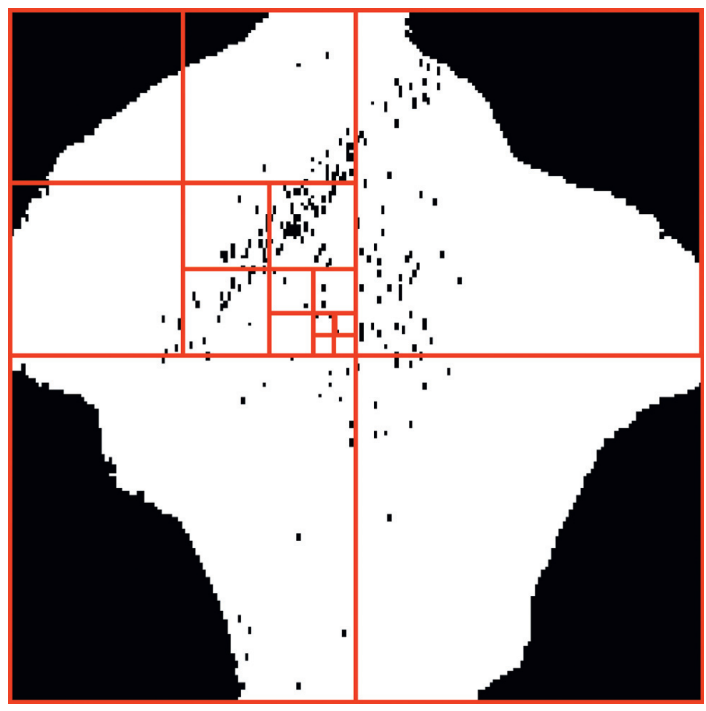

(b)

Figure 3: The calculation process of the box dimension of the rock mesodamage area. (a) Damage evolution of sandstone particles in the form of a binary image (with confinement). (b) Schematic diagram of the box division process.

$$
\varepsilon_{c 0}=-\frac{f_{c}}{E_{o}}
$$

\subsection{Using the Box-Counting Method and Fractal Analysis of} Images. B.B. Mandelbrot proposed fractal damage theory. This theory studies and describes irregular, highly complex, unstable phenomena in nature. The fractal theory is able to describe complex objects in the physical world quantitatively and can be used to reveal the damage mechanism in a rock mass. Its calculation methods include the box dimension, Hausdorff dimension, and information dimension algorithms. Since the box-counting dimension can intuitively reflect the degree of occupancy of the target in the study area and it is easy to calculate and measure, it has been used widely in various fields. In this study, the box dimension calculation with the self-similarity method has been selected, which is defined as $[25,26]$

$$
D s=\lim _{k \longrightarrow \infty} \frac{\lg N r_{k}(A)}{\lg 1 / r_{k}},
$$

where the self-similar fractal dimension of the damaged region is $D s$ and the developed reducing sequence with the element's square box size is $r_{\mathrm{k}}$. The least number of grids necessary for covering the target set $A$ with a square box of size $r_{\mathrm{k}}$ is $N r_{\mathrm{k}}(A)$.
Based on the research foundation of fractal theory, this paper aims to use box dimension to study and analyze the fractal of mesoscale failure element area of irregular sandstone particles with different loading conditions. The fractal dimension of the mesoscale failure element area of irregular sandstone particles with different loading conditions at different stress levels is calculated, and the corresponding damage degree of the medium is determined. A binary image in Figure 3(a) is a representation of the mesoscale fracture evolution of irregular sandstone particles under different loading steps. Since the size of the box and pixel is relatable, the actual size of the pixel is equal to the minimum size of the box. Therefore, the smaller size of the box yields higher image resolution and accuracy of the calculation result. The resolution of the image is $500 \times 500$ pixels in this paper. The resolution of the image is $500 \times 500$ pixels in this paper.

Figure $3(\mathrm{~b})$ is the box covering various regions, which is dividing the mesoelement failure area into a small square grid with $r_{\mathrm{k}}$ side length (the length of each image pixel is described as 1 in this paper); then count the number $\mathrm{Nr}_{\mathrm{k}}$ of all boxes comprising failure element region. A dichotomy is used to construct $r_{\mathrm{k}}$ in this paper. If the failure element distribution in this area satisfies the fractal features, the formula shows that "when the $r_{k} \longrightarrow 0, \operatorname{lgNr} r_{k} / \lg r_{k} \longrightarrow D$, it can be seen that the fractal dimension of the failure element field (acoustic emission field) in this area is D. Hence, in the 
double logarithmic coordinate system, the data points $\left(\lg r_{k}\right.$; $\lg N r_{k}$ ) are linearly fitted by the least square method, and the straight line equation" can be found:

$$
\lg N r_{k}=D \lg r_{k}+b \text {. }
$$

In the expression above, the box-counting dimension of the field of the failure element in the area is expressed in terms of $D$. Based on the above principle, Matlab programming is used to automatically mesh and statistics the acoustic emission evolution image of the mesoscale failure of the rock particle, and calculate the corresponding fractal dimension. The process for calculation is demonstrated in Figure 4.

\section{Establishment of Numerical Model}

For better comprehension of the fracture behavior and damage evolution characteristics of such rock particles, it is necessary to simulate the fracture evolution process of irregularly shaped particles under different loading conditions. Revealing the fracture process of a single particle under load conditions is an important step in understanding particle fragmentation. However, usually, the fracture behavior of single particles is affected by their loading conditions, shape, and size [3]. Therefore, DIP techniques (see Section 2.1) are combined with finite element modeling. In the finite element method, the research objects need to be divided into many small grids. Since many pixels make up a digital image, pixels can be regarded as mesh in finite elements (Figure 5). The entire characterization image can be transformed into several finite element grids, and then the material parameters are assigned to each material component according to the characterized color. The nonuniform coefficients of the different components are inputted into the numerical model. Thereby, a numerical model considering the real mesostructure of the material is established.

This study uses the rock failure process analysis system (RFPA2D) for numerical simulation; RFPA2D can simulate the microscopic failure evolution and failure process of rock through two-dimensional FEM. Thorough and detailed descriptions can be found elsewhere about this simulator [27]. Here, we incorporate digital image processing into the rock failure process analysis code (RFPA2D) and establish a quasiactual model. RFPA takes the rock heterogeneity into account $[10,28]$, culminating in the RFPA2D-DIP numerical simulation system $[22,28,29]$. The constitutive model of damage to the element is shown in Section 2.2. The numerical model consists of two materials: a sandstone matrix and a calcite mineral. In the numerical calculation, taking into account the nonuniformity of the material, we assume that the mechanical parameters of the matrix elements of sandstone and calcite obey the Weibull distribution function and is expressed as $[6,30,31]$

$$
f(u)=\frac{m}{u_{o}}\left(\frac{u}{u_{o}}\right)^{m-1} \exp \left(-\frac{u}{u_{o}}\right)^{m},
$$

where $u$ represents the parameter of the mechanical properties of the material medium, the average value of the mechanical property parameters is represented by $u_{0}, m$ represents the property parameter of the distribution function, reflecting the uniformity of the material medium, and $f(u)$ is the statistical distribution density of the mechanical properties of the material. In the model, the heterogeneity of calcite and sandstone is considered, and the Monte-Carlo method is used to assign the mechanical parameters of the mesoelements [32, 33].

Figure 5 exemplifies the finite element model (FEM) based on an irregular CT slice. The mechanical parameters of each mesomedium in Table 1 are quoted from previous research results $[10,34]$. Figure 6 is a mechanical loading model of two irregular particles based on DIP technology and RFPA2D software under different loading conditions. A $5 \mathrm{~mm}$ thick loading plate is fixed on the top and bottom of the particle test piece, the loading plate has uniform elasticity, the elastic modulus is $200 \mathrm{GPa}$, Poisson's ratio is 0.25 , and the compressive strength is $1000 \mathrm{GPa}$ [6]. P is the axial pressure of the model. The whole process adopts constant displacement loading control method and uses plane stress analysis to simulate the test. The initial displacement is $0.0002 \mathrm{~mm}$, the single-step increment is $0.0004 \mathrm{~mm}, Q$ is the horizontal constraint, and $Q$ is $0.5 \mathrm{MPa}$.

\section{Results and Discussion}

4.1. Stress Distribution Characteristics and Confinement Effect. Figure 7 shows the elastic modulus and internal maximum principal stress distribution in the initial stage of the specimen loading. In Figure 7, the brighter the area, the greater the stress, and vice versa. It can be seen from Figure 7 (b) that the internal stress distribution is not uniform due to the existence of mesouniformity, and the unconstrained particles lead to the concentrated stress distribution due to the small contact area between the upper and lower end faces and the loading plate. And the stress concentration on both sides of the constrained particles is caused by the constant confinement on both sides. There is significant stress concentration between the sandstone and the calcite at the interface (a weak structural plane). This shows that the existence of calcite veins in sandstone and the heterogeneity of the mesostructure have a significant influence on the stress distribution.

Due to the different loading conditions, the irregular particles produced significantly different mechanical responses during the breakage process. As shown in Figures 8 and 9, the presence of confinement increases the initial stiffness of the particles compared to the particles without confinement, resulting in an increase in particle strength. There are obvious brittle-ductile transition processes in load-displacement curves under different loading conditions, and the load-displacement curve of the stationary phase of the constrained particle showed strong jagged fluctuations during the loading process, which is caused by the complex stress response caused by the microfracture inside the particle. In the subsequent breakage process, more acoustic emission signals are generated and more energy is released, which shows better ductility than unconstrained particles. This result seems to support the research conclusion of Tang et al. [5]. With confinement, particles are in breakage in a 


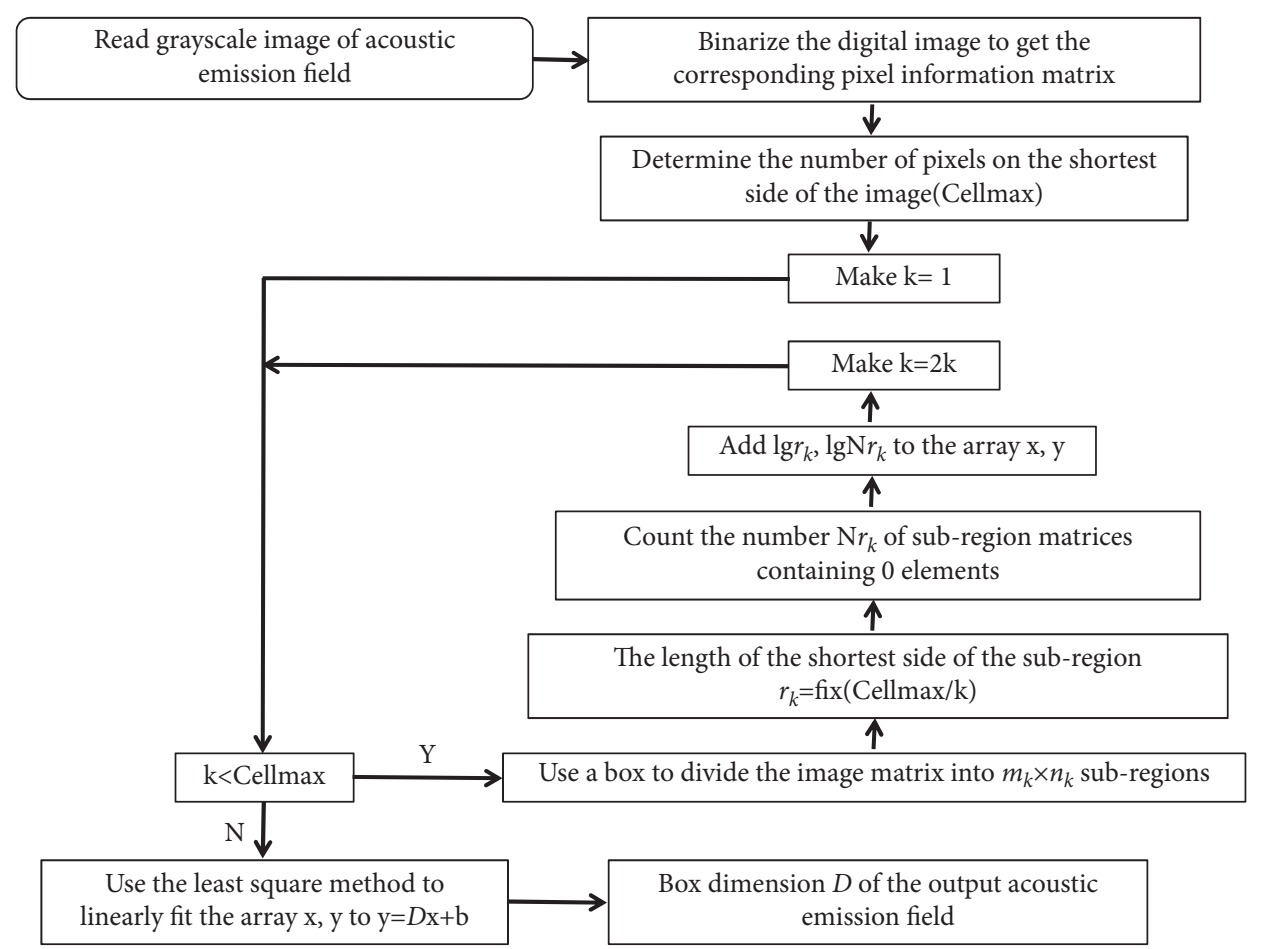

FIGURE 4: Schematic diagram of box dimension calculation based on acoustic emission field.

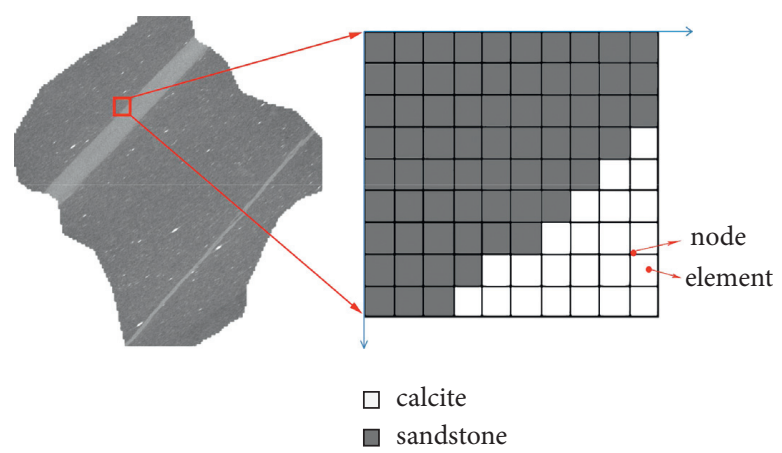

Figure 5: Finite element conversion process of sandstone particle digital image.

TABLE 1: Material parameters of a rock sample.

\begin{tabular}{lccccc}
\hline Material & Elastic modulus $(\mathrm{GPa})$ & Compressive strength $(\mathrm{MPa})$ & Poisson ratio & Compression-tension ratio & Internal friction angle $\left(\mathrm{C}^{\circ}\right)$ \\
\hline Sandstone & 108.2 & 118 & 0.16 & 14 & 35 \\
Calcite & 80.5 & 101 & 0.30 & 10 & 30 \\
\hline
\end{tabular}
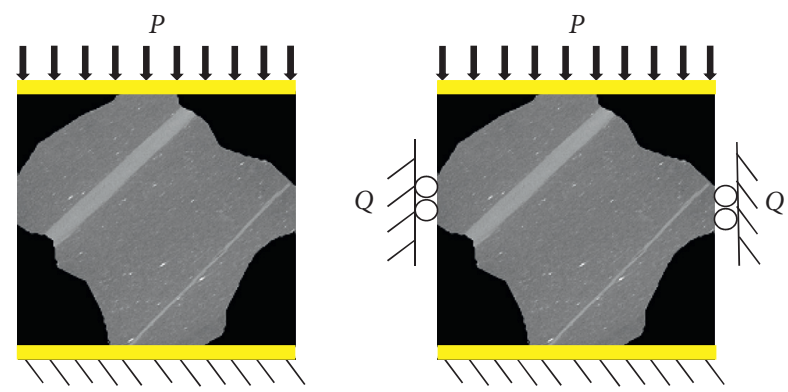

Figure 6: Mechanical loading diagram of the numerical model. more ductile manner, and the maximum load required for failure is $245 \mathrm{~N}$ higher than the maximum load required for without confinement particles, which is about $11.9 \%$ of the maximum load, and without confinement, particles are in breakage in a more brittle manner.

4.2. Acoustic Emission Evolution Characteristics. The evolution process of rock mass damage is essentially the use of dissipated energy to form damage, leading to loss of strength. The release of elastic energy stored in the rock mass unit is the internal cause of the sudden failure of the rock mass unit. 


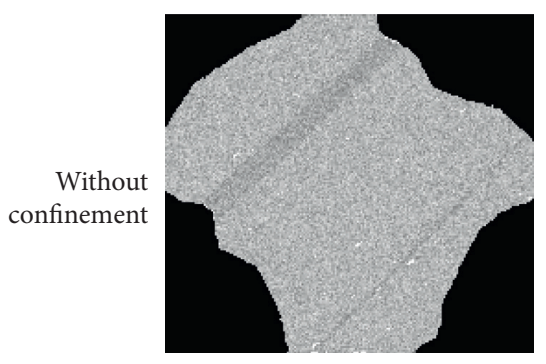

(a)

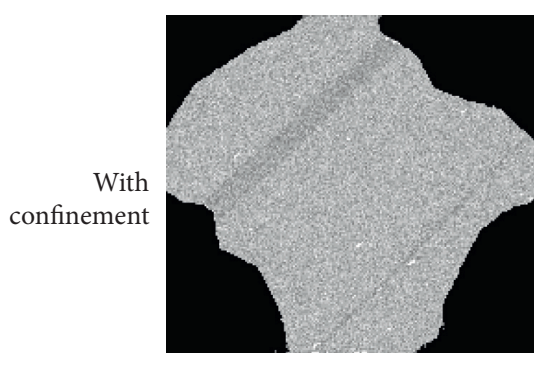

(c)

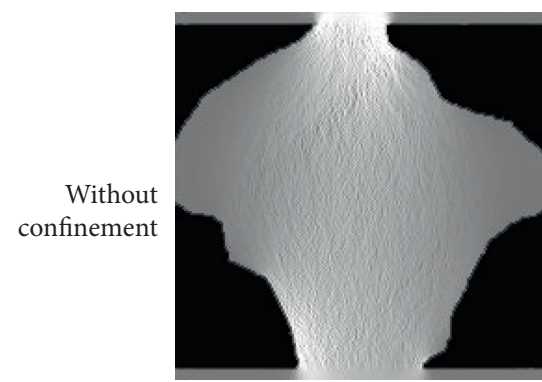

(b)

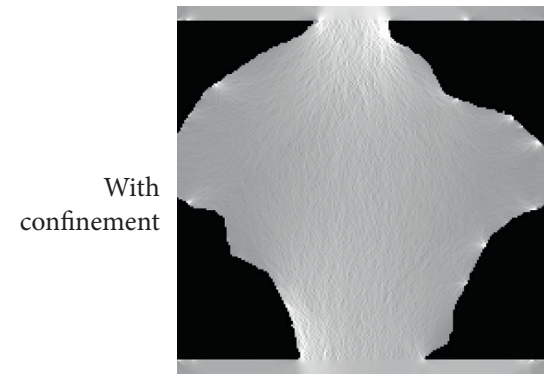

(d)

FIGURE 7: Distribution of the elastic modulus and maximum principal stress of the specimen during the initial loading.

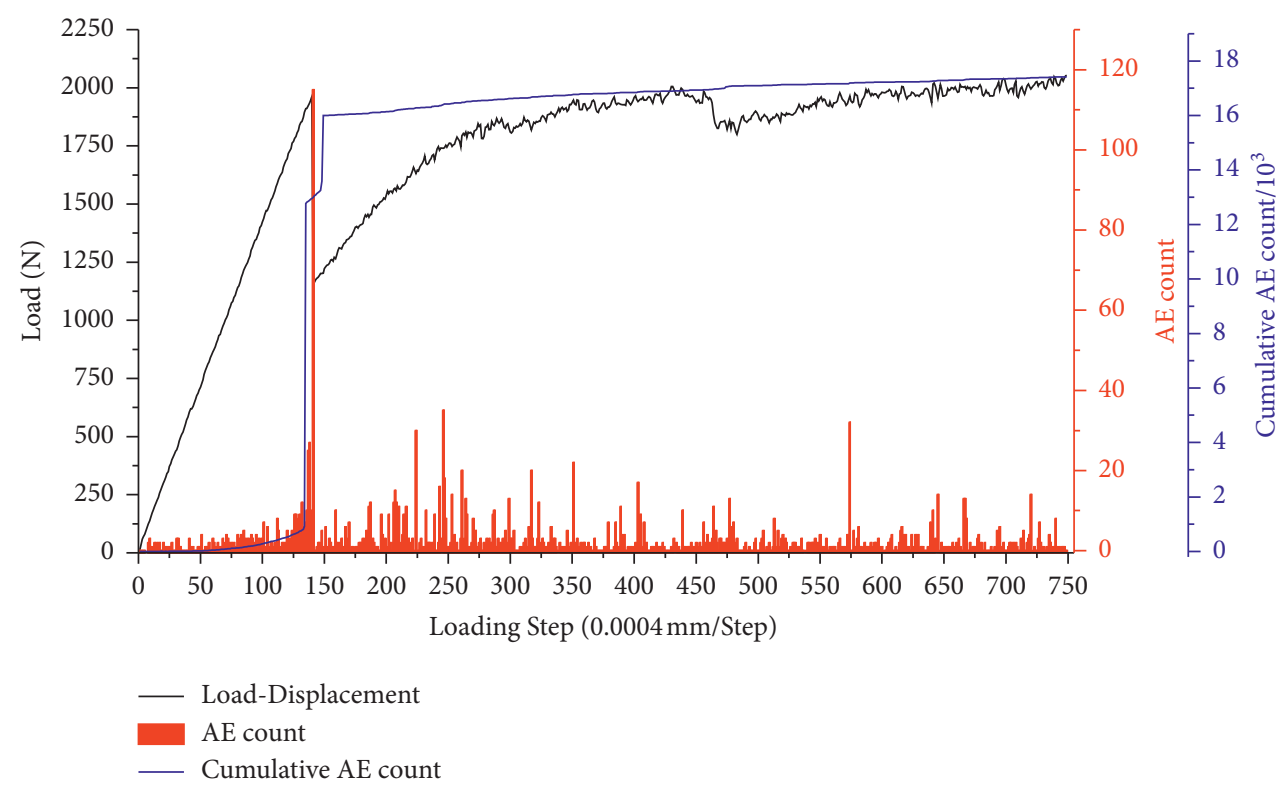

Figure 8: Load-AE and cumulative AE displacement curves of a particle under diametral loading with confinement.

Acoustic emission refers to the elastic wave emitted by the rapid release of local energy of the rock under the action of a load and is an effective tool for studying the internal damage evolution process of the rock. In RFPA2D, due to the failure of the sample element, elastic energy stored in the deformation process is released. Assume that the failure of every sample element represents the source of the acoustic emission. By recording the energy release for respective damaged elements and their number, RFPA2D is able to simulate the acoustic emission activity [5]. Figures 8 and 9 are trend graphs of loaddisplacement, $\mathrm{AE}$ count, and cumulative $\mathrm{AE}$ count varying with loading step under different loading conditions. In the figure, it can be seen that the load-displacement curve is synchronized with the AE-load step change. For the without confinement particle specimens, in the early stage of loading (steps 1-132), there are fewer acoustic emission events, the $\mathrm{AE}$ signal is relatively weak, the stress is in the linear elastic stage, and the cumulative acoustic emission events show a gentle change and microcracks initiate. The cumulative acoustic emission events show linear growth in the middle (steps 132-139) loading period; after the loading reaches the maximum load, the acoustic emission events are the most, the 


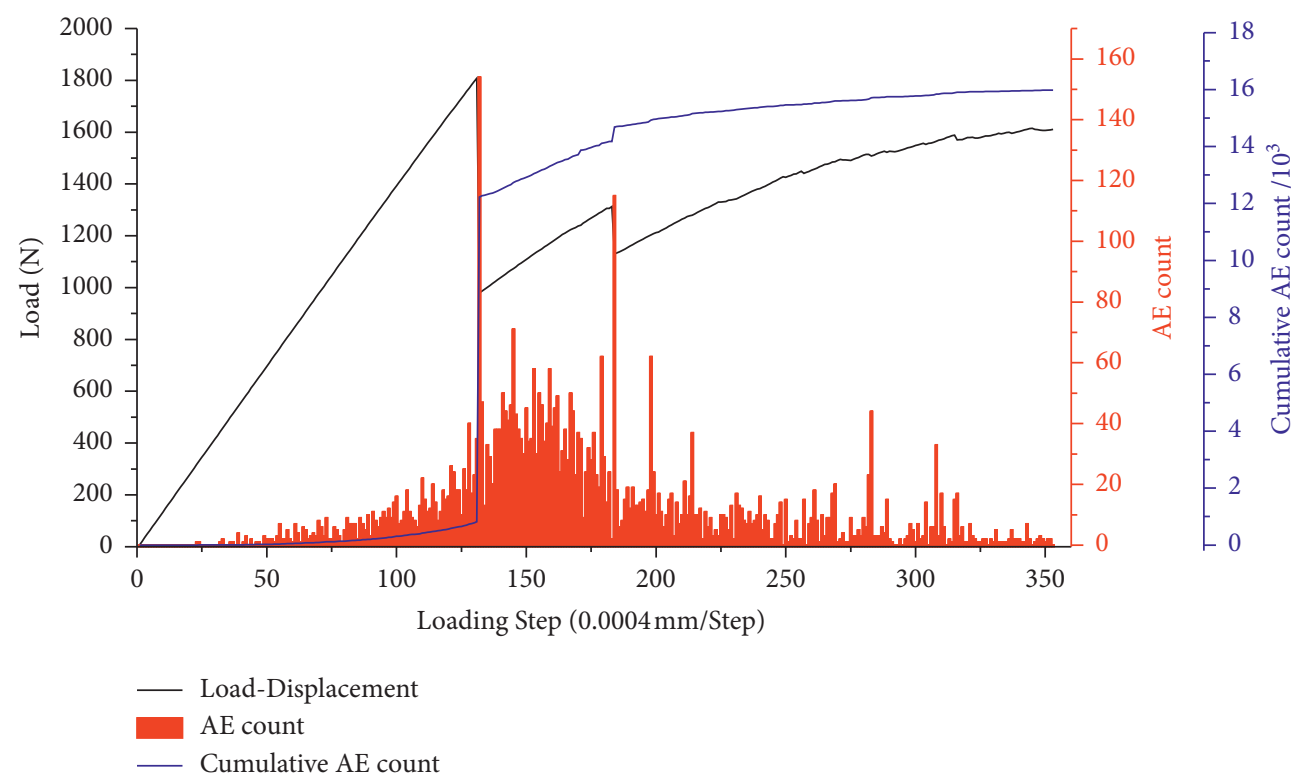

Figure 9: Load-AE and cumulative AE displacement curves of a particle under diametral loading without confinement.

AE signal is the strongest, a strong load drop phenomenon occurred, and the cracks extended and expanded sharply until they penetrated; the particles break (steps 132-139 in Figure 10) to form a macrofragmentation zone and consume most of the energy of the whole fracture process. In the later stage of loading (steps 139-350), in addition to the phenomenon of load drop again in step 189, the cumulative acoustic emission event showed a gentler change with a smaller change, and the particles completely broke. For the with confinement particle specimens, in the early stage of loading (steps 1-141), there are fewer acoustic emission events, the AE signal is relatively weak, the stress is in the linear elastic stage, there are obvious cracks, and the cumulative acoustic emission events show a gentle change. The cumulative acoustic emission event showed a sharp change in the middle of loading (steps 141-147), the acoustic emission event produced a jump growth when the maximum load is reached, the signal is extremely strong, there is a strong load drop phenomenon, and the particles break (steps 141-147 in Figure 10) to form a macrofragmentation zone and consume most of the energy of the whole fracture process. The load decreases and the AE value decreases significantly after the particle breakage at the later stage of loading (steps 147-749), but because the particle still has a certain residual strength, it still has a certain bearing capacity, and with the increase of the axial load, the original cracks further expanded and many new cracks were produced at the same time the cumulative change of the acoustic emission event is small. The particles completely break at this time. Accumulated acoustic emission events indicate that, with confinement particles consuming more energy during the breakage phase than without confinement particles (Figure 8), the greater the energy given to the particles, the finer the particles they produce and the better the final breakage effect.
4.3. Analysis of the Crack Propagation and Fracture Evolution of the Particle. Figure 10 is the evolution diagram of acoustic emission and elastic modulus of irregular particle specimen's breakage process under different loading conditions. In the acoustic emission diagram, white indicates that the element has a compression-shear failure in the current loading step, black indicates that the elements have been completely damaged in the current loading step, and yellow indicates that the element has a tensile failure in the current loading step.

The figure clearly indicates that, in the unconstrained particle specimen, the initiation of cracks starts at the middle of the calcite veins. The initial crack and the horizontal plane of the specimen are about $45^{\circ}$ angle from the cementation of the calcite vein and the sandstone (weak surface) and extend along the right upper part of the calcite vein. As the axial stress increases, the crack changes its propagation direction and grows steadily along the direction of the maximum principal stress. It can be seen from the acoustic emission evolution diagram that cracks initiation and expansion are caused by tensile failure. A large amount of tensile failure occurred inside the specimen when loaded to step 139, which led to the penetration of cracks. This is due to the low tensile strength of sandstone. In the without confinement compression state, the tensile stress first reaches the tensile strength and eventually forms a tensile failure. With confinement particle specimen, Tang et al. showed that the cracks were mainly caused by the progressive instability near the upper load point and then started in the shear zone between the upper load point and the lower-left load point [5]. However, due to the fact that the real mesostructure and mesoheterogeneity of particles are considered in this paper, the crack is formed along the middle part of the calcite vein and extends along the direction of maximum principal stress. A second tensile crack is formed along the lower-left part of the calcite vein when loading to step 145; with the 


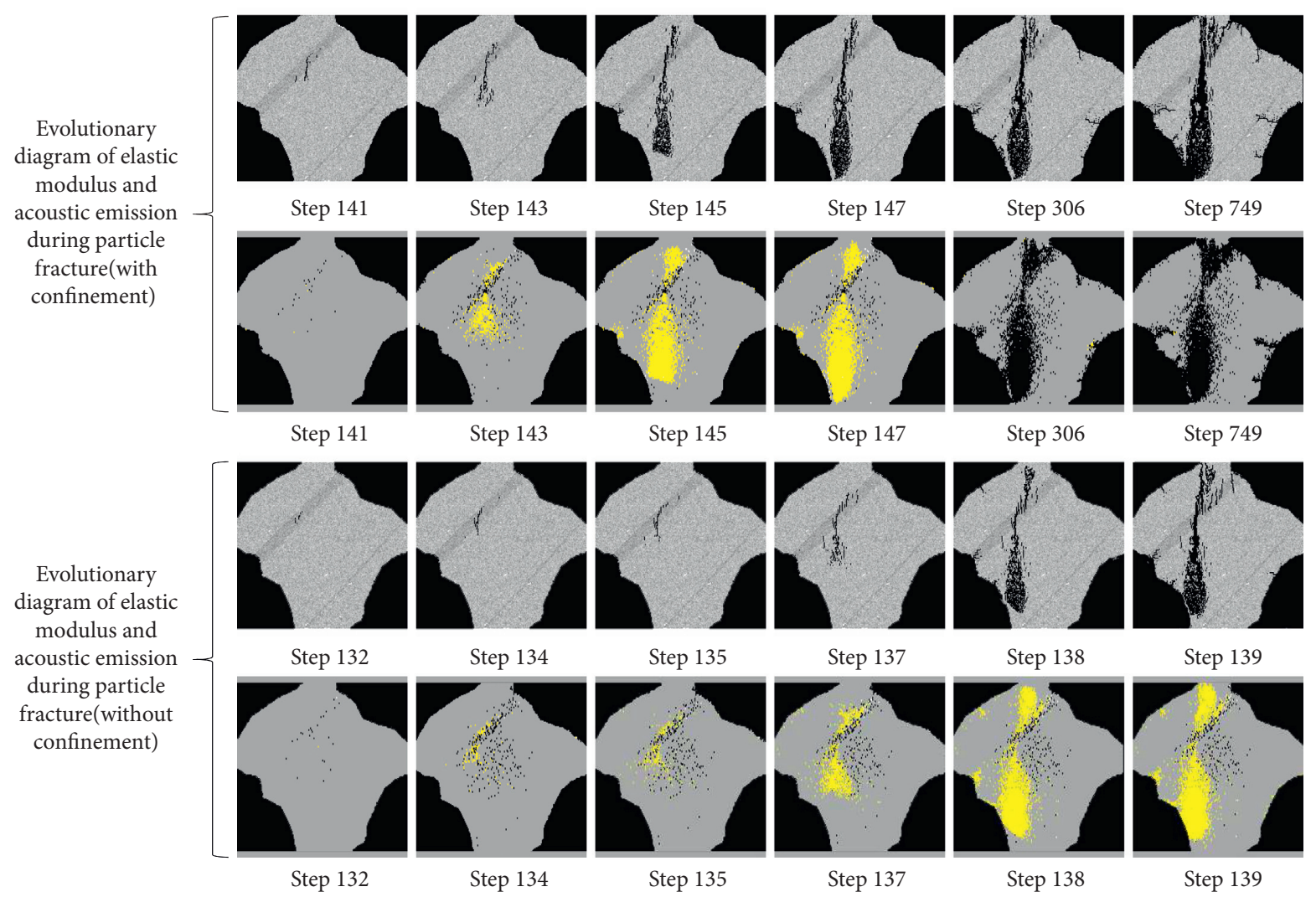

Figure 10: Evolutionary diagram of acoustic emission and elastic modulus of irregular particles during fracture.

increase of axial stress and the influence of confinement, a large amount of tensile failure occurred inside the specimen when loaded to step 147, which led to the penetration of the main crack and eventually formed tensile failure. Although the breakage of the particles under both loading conditions is tensile type failure, the with confinement particles show a more destructive nature, which is consistent with the study of Tang et al. [5].

Whiten et al. proposed two breakage functions to describe two different breakage modes; the first is the "catastrophic" breakage mode which produces a small number of coarse particles, and the second is to produce fine particles between the contact point between the liner of the crusher and the particles and the adjacent loading point [35]. Our study shows that the particles produce two different sizes of particles during the breakage: one is coarse particles due to tensile failure and the other is fine particles due to shear or compression failure near the load point (Figure 10). However, our results seem to be consistent with these conclusions.

\subsection{Fractal Characteristics and Mesoscale Fracture Damage} Degree Based on Box Dimensions. The microfracture evolution can be described quantitatively using the damage variable; however, the damage variable does not adequately reflect the spatial distribution of microfractures, and yet the spatial relationships of microfractures are directly related to the macroscopic fracture of the sample. Xie et al. showed that the fracture process of rock has self-similarity, which is manifested by the fact that the fracture process has fractal characteristics [36]. Every microfracture is accompanied by a measurable transient elastic wave generated by the rapid release of sound energy, known as acoustic emission. These acoustic emissions can be used to characterize the entire failure process of a rock, and hence the acoustic emission of rock failure has fractal features. Thus, using the fractal dimension determined from the acoustic emission field as the characteristic parameter to illustrate the evolution of mesoscale damage of the rock particles quantitative analysis of the evolution of mesoscale failure of the rock particles, damage evolution, and macrodamage characteristics of the mesoelement of the material can be done effectively. This data can be used to develop a relationship between the mesoscale fracture damage degree of the rock $\omega$ (hereinafter referred to as "fracture damage degree") and the fractal dimension value $D$ corresponding to the "acoustic emission field," which can be expressed as

$$
\omega=\frac{D-D 0}{D^{\max }-D 0}
$$

where $D$ is the fractal dimension of the damaged area of the mesoscopic element of the rock particles after stress loading; $D_{0}$ is the fractal dimension of the initial damage area of the mesoscopic element of the rock particles before stress loading; $D^{\max }$ is the fractal dimension when the mesoscopic element of the rock particles reaches the maximum damage area, for plane problems, $D^{\max }=2$, and for three- 


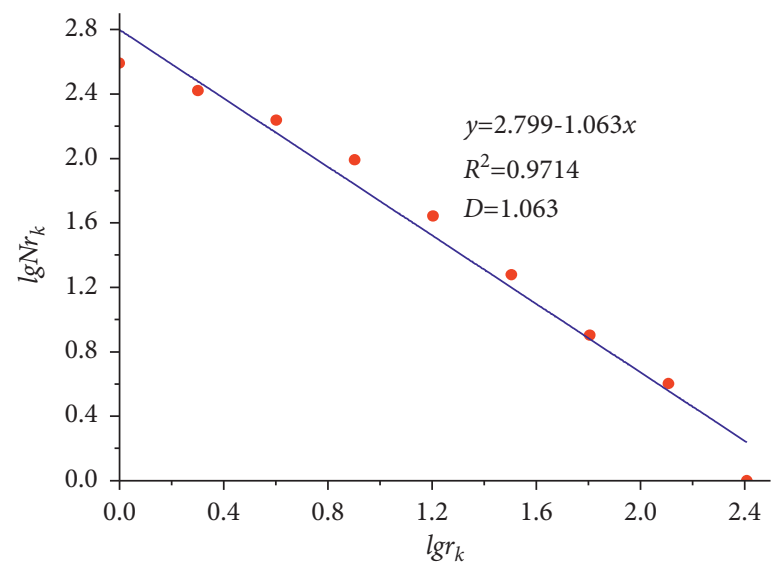

(a)

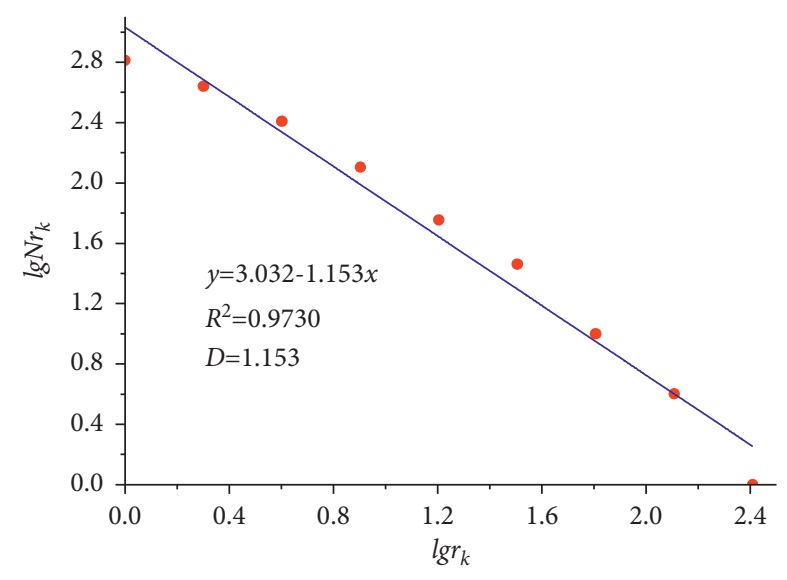

(b)

Figure 11: Calculation results of fractal dimension of the irregular particle (without confinement).

dimensional problems, $D^{\max }=3$. It can be seen from (11) that, before stress loading, $\omega=0$; that is, the degree of material damage is 0 . When the rock particles are in complete failure under the action of stress, it reaches $D_{=} D_{\text {max }}$, then $\omega=1$, and the material damage degree is 1 .

In order to study the fractal characteristics of the mesoscale fracture evolution of irregular sandstone particles, the fractal dimension (see Section 2.3 in this paper) will be used to characterize the damage degree and load of rock particle breakage. Based on MATLAB platform, the fractal dimension under different stress conditions is calculated. Figure 11 shows the fractal fitting diagrams of irregular particle (without confinement) breakage when the stress level is $90 \%$ and $100 \%$, respectively. The correlation coefficients are $R^{2}=0.9714$ and $R^{2}=0.9730$, respectively, indicating that the fractal dimension has a high degree of confidence, and its values are $D=1.603$ and $D=1.153$, respectively. Table 2 shows the fractal dimensions and damage degree of the sample under different stress conditions.

Figure 12 shows the relationship between different stress levels and fractal dimensions of the specimen under different loading conditions, and Figure 13 shows the relationship between the fracture damage degree and the different stress levels of the specimen under different loading conditions. It can be seen from Figures 12 and 13 that, under different load conditions, as the stress increases, the internal damage for the sandstone particles continues to accumulate, the fracture damage degree and fractal dimension are constantly increasing, and their changes are synchronized. The load of the particle damage area and fractal dimension are positively correlated, and the increase of fractal dimension is synchronized with the change of damage. Figure 13 describes and corroborates the effect of loading conditions on particle damage degree from the perspective of the fractal. Under different loading conditions, sandstone particles are in the elastic stage when the stress level is $10 \%$, both the fracture damage degree and the fractal dimension value are 0 , indicating that there is no damage inside the sandstone particles. The fractal dimension of the particles under different loading conditions will increase rapidly when the stress level is lower than $50 \%$, in which the fractal dimension of the without confinement particles is generally higher than that of the with confinement particles, which is due to the existence of confinement increases the initial stiffness of the particles, resulting in an increase in the strength of the with confinement particles and a smaller amount of microfracture with a random and isolated distribution in the whole sample under the same stress conditions. The deformation of the sample is more uniform, and the interaction between the microcracks is not obvious, which reflects the low degree of damage of the sample and the random characteristics of material properties, and its damage shows a certain lag. Finally, at a stress level of $100 \%$, the degree of fracture damage is 0.733 , and the fractal dimension value of the with confinement particles is 1.466 . The fractal dimension value of the without confinement particles is 1.153 when the stress level is $100 \%$, and the fracture damage degree is 0.577 , all of which are smaller than the with confinement particles. The reason for further analysis shows that the final failure mode of with confinement particles is more complicated than that of without confinement particles, the breakage is more complete, and the damage is more serious, so the damage degree and the fractal dimension are larger. Therefore, the greater the degree of fracture damage is, the more severe the particle will eventually fracture, and the better the crushing effect, the larger the value of the fractal dimension and the more complex the particle's final failure mode.

Figure 14 shows the adequate relationship between the fractal dimension of particle breakage and load at different stress levels under different loading conditions, the correlation coefficients are $R^{2}=0.9872$ and $R^{2}=0.9624$, respectively, and the fitting relationship expressions are $P=180+1319.44 D^{1.49}$ and $P=188+1347.69 D$, respectively. The breakage load of without confinement particles and the fractal dimension approximately follow the power exponential relationship; the breakage load of the with confinement particles and the fractal dimension approximately follow a linear relationship. As shown in Figure 14, with the 
Table 2: The fractal dimension value and damage degree of the specimen under different stress conditions.

\begin{tabular}{lccccccccccc}
\hline & & \multicolumn{1}{c}{ Stress level } & & & & \\
Numerical sample & & $10 \%$ & $20 \%$ & $30 \%$ & $40 \%$ & $50 \%$ & $60 \%$ & $70 \%$ & $80 \%$ & $90 \%$ & $100 \%$ \\
\hline \multirow{2}{*}{ Without confinement } & $D$ & 0 & 0.182 & 0.416 & 0.588 & 0.688 & 0.837 & 0.878 & 0.971 & 1.063 & 1.153 \\
& $\omega$ & 0 & 0.091 & 0.226 & 0.294 & 0.344 & 0.419 & 0.439 & 0.485 & 0.532 & 0.577 \\
\hline \multirow{2}{*}{ With confinement } & $D$ & 0 & 0.153 & 0.288 & 0.563 & 0.686 & 0.860 & 0.913 & 0.980 & 1.070 & 1.466 \\
& $\omega$ & 0 & 0.077 & 0.144 & 0.282 & 0.343 & 0.430 & 0.457 & 0.490 & 0.535 & 0.733 \\
\hline
\end{tabular}

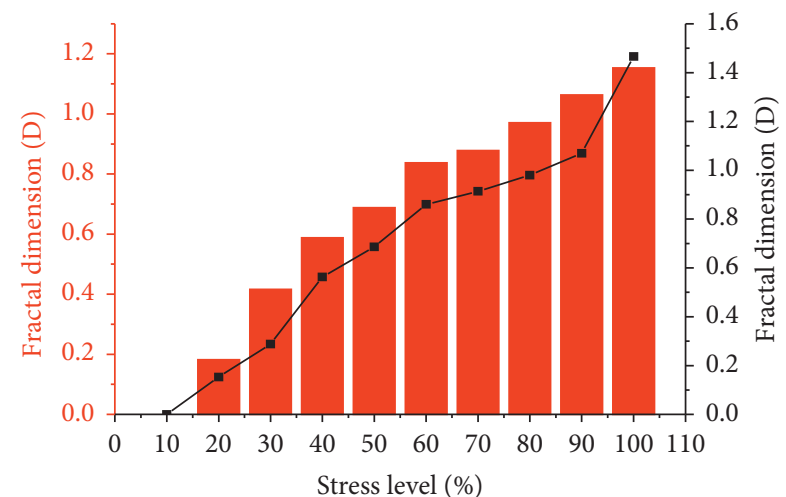

Without confinement - With confinement

Figure 12: Relationship between stress levels and corresponding fractal dimensions.

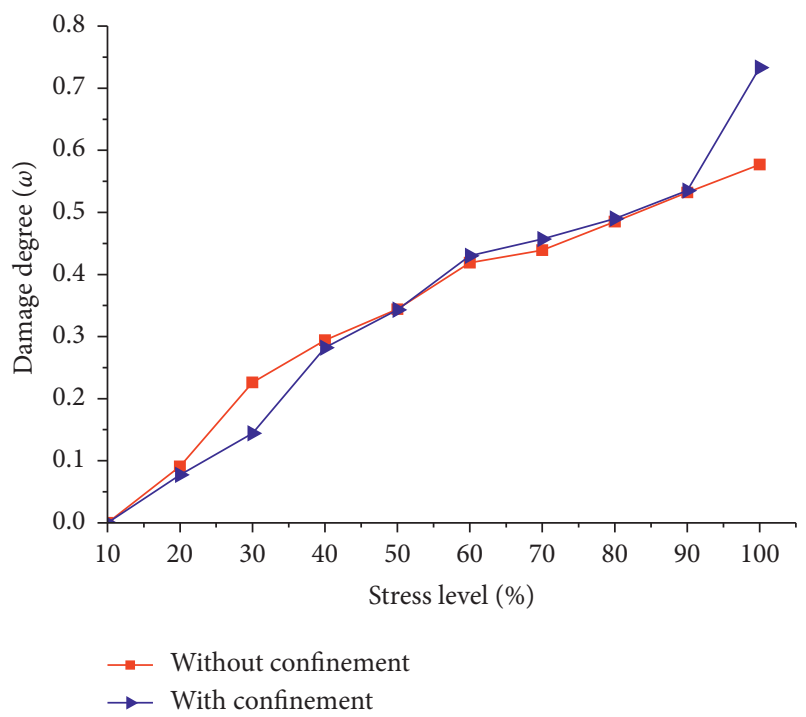

FIgURE 13: Relationship between damage degree and different stress levels.

increase of the fractal dimension, the load of sandstone particles continues to increase. This is due to the development, expansion, and penetration of different-scale cracks within the particles, which lead to the destruction of the particles; it is the result of the initial mesoscopic damage in the internal particle structure developing to the macroscopic breakage. The higher the breakage load is, the more developed the internal cracks of the particle are, and the more the damage elements will be generated, the larger the

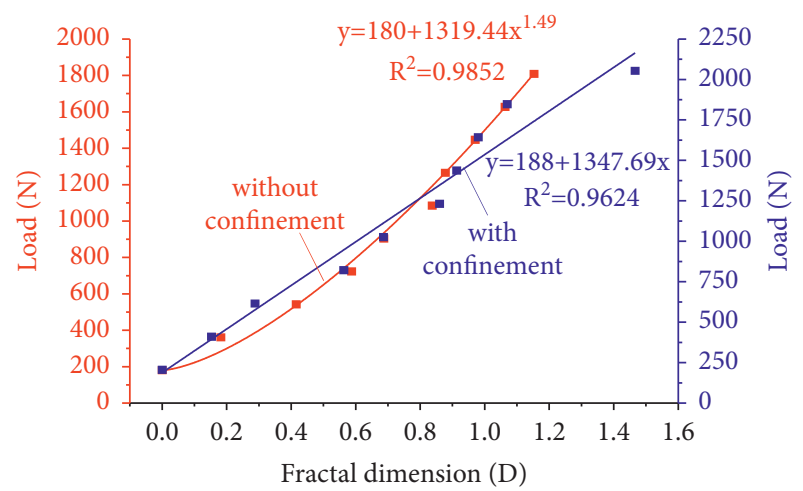

FIgURE 14: Relationship between diametral load and fractal dimension under different loading levels.

fracture damage degree and fractal dimension are; the fracture damage degree and fractal dimension can better characterize the damage evolution process of sandstone particle mesoscale fracture. Therefore, the load of particle crushing can be quantitatively described by the fractal dimension, and the fracture damage degree can be used to characterize the damage of the particle.

In summary, the fractal dimension can be used to characterize the complexity of irregular particle failure and can be used to predict failure strength, and the degree of damage can be characterized by the fracture damage degree. Therefore, it is very effective to apply fractal theory to rock particle fragmentation; we can use the method of this paper to calculate the fracture damage degree and fractal dimension to analyze the damage mechanical characteristics of irregular particles, which provides a new way to quantitatively evaluate the damage degree and crushing effect of irregular particles under load.

\section{Conclusion}

(1) A box dimension program for mesoscale failure analysis of irregular rock particles was developed based on the MATLAB platform, and the calculation method of fractal dimension of irregular rock particles mesoscale failure is proposed. This method can quantitatively describe the damage evolution process of irregular rock particles.

(2) The maximum fracture damage degree and fractal dimension of with confinement particles are 0.733 and 1.466 , respectively, and the without confinement particles are 0.577 and 1.153 , respectively. The final failure mode of with confinement particles is more 
complicated than that of without confinement particles, the breakage is more complete, and the damage is more serious. Therefore, the greater the degree of fracture damage is, the more severe the particle will eventually fracture, and the better the crushing effect, the larger the value of the fractal dimension and the more complex the particle's final failure mode.

(3) The fractal model of irregular rock particles breakage under different loading conditions is established; that is, the fractal dimension of with confinement particles and load are approximately linear, and the fractal dimension of without confinement particles and load are approximately powered exponential relationship. Fractal dimension can be used quantitatively to describe a load of particle breakage under different loading conditions to explore the inherent law of rock particle breakage.

\section{Data Availability}

The data used to support the findings of this study are available from the corresponding author upon request.

\section{Conflicts of Interest}

The authors declare no conflicts of interest.

\section{Acknowledgments}

This work was supported by the Science and Technology Support Project of Guizhou Province, China (Grant no. [2021] general 516); the National Natural Science Foundation of China (Grant nos. 51774101, 51964007, and 41962008). These sources of supports are gratefully acknowledged.

\section{References}

[1] C. M. Evertsson, "Cone crusher performance," Ph.D. thesis, Chalmers University of Technology, Gothenburg, Sweden, 2000.

[2] V. S. Vutukri, R. D. Lama, and S. S. Saluja, Handbook on Mechanical Properties of Rocks, pp. 87-140, Trans Technical Publications, Stafa-Zurich, Switzerland, 1974.

[3] O. Tsoungui, D. Vallet, and J. C. Charmet, "Numerical model of crushing of grains inside two-dimensional granular materials," Powder Technology, vol. 105, pp. 190-198, 1999.

[4] G. R. McDowell and O. Harireche, "Discrete element modelling of soil particle fracture," Géotechnique, vol. 52, no. 2, pp. 131-135, 2002.

[5] C. A. Tang, X. H. Xu, S. Q. Kou, P.-A. Lindqvist, and H. Y. Liu, "Numerical investigation of particle breakage as applied to mechanical crushing-part I: single-particle breakage," International Journal of Rock Mechanics and Mining Sciences, vol. 38, no. 8, pp. 1147-1162, 2001.

[6] Y. J. Zuo, Q. Zhang, T. Xu, Z.-H. Liu, Y.-Q. Qiu, and W.-C. Zhu, "Numerical tests on failure process of rock particle under impact loading," Shock and Vibration, vol. 2015, pp. 1-12, 2015.
[7] Bo Zhou, D. Wei, Ku Quan, J. Wang, and A. Zhang, "Study on the effect of particle morphology on single particle breakage using a combined finite-discrete element method," Computers and Geotechnics, vol. 122, pp. pp1-12, 2020.

[8] D. Wei, B. Zhao, D. Dias-da-Costa, and Y. Gan, "An FDEM study of particle breakage under rotational point loading," Engineering Fracture Mechanics, vol. 212, pp. 221-237, 2019.

[9] Y. Wang, X. Shang, and K. Peng, "Relocating mining microseismic earthquakes in a $3-\mathrm{D}$ velocity model using a windowed cross-correlation technique," IEEE Access, vol. 8, pp. 37866-37878, 2020.

[10] H. Liu, Y. J. Zuo, Z. H. Wu, and W. Sun, "Fractal analysis of mesoscale failure evolution and microstructure characterization for sandstone using DIP, SEM-EDS, and micro-CT," International Journal of Geomechanics, vol. 21, no. 9, Article ID 04021153, 2021.

[11] C. Liang, Y. Wang, G. Tan, L. Zhang, Y. Zhang, and Z. Yu, "Analysis of internal structure of cement-stabilized macadam based on industrial CT scanning," Advances in Materials Science and Engineering, vol. 2020, no. 2, pp. pp1-10, 2020.

[12] Y. Li, Y. Zhao, Y. Jiang, Bo Zhang, H. Song, and B. Liu, "Characteristics of pore and fracture of coal with bursting proneness based on DIC and fractal theory," Energies, vol. 13, 2020.

[13] X. Y. Shang, Y. Wang, and R. Y. Miao, "Acoustic emission source location from P-wave arrival time corrected data and virtual field optimization method," Mechanical Systems and Signal Processing, vol. 163, Article ID 108129, 2022.

[14] Q. Yu, W. Zhu, C. Tang, and T. Yang, "Impact of rock microstructures on failure processes-Numerical study based on DIP technique," Geomechanics and Engineering, vol. 7, no. 4, pp. 375-401, 2004.

[15] Z. H. Wu, Y. J. Zuo, S. Y. Wang et al., "Numerical simulation and fractal analysis of mesoscopic scale failure in shale using digital images," Journal of Petroleum Science and Engineering, vol. 145, pp. 592-599, 2016.

[16] J. Lemaitre, Evaluation of Dissipation and Damage in Metals Submitted to Dynamic Loading, Mechanical Behavior of Materials, National Technical Reports Library, Guthrie, Gregory, 1972.

[17] C. A. Tang, L. G. Tham, S. H. Wang, H. Liu, and W. H. Li, “A numerical study of the influence of heterogeneity on the strength characterization of rock under uniaxial tension," Mechanics of Materials, vol. 39, no. 4, pp. 326-339, 2007.

[18] W. C. Zhu, J. Liu, C. A. Tang, X. D. Zhao, and B. H. Brady, "Simulation of progressive fracturing processes around underground excavations under biaxial compression," Tunnelling and Underground Space Technology, vol. 20, no. 3, pp. 231-247, 2005.

[19] C.-1. Wang, Z. Chen, Z.-f. Liao et al., "Experimental investigation on predicting precursory changes in entropy for dominant frequency of rockburst," Journal of Central South University, vol. 27, no. 10, pp. 2834-2848, 2020.

[20] Q. Xie, C. X. Jiang, and J. M. Ling, Meso-Mechanics of RockExperiment and Analysis, Southwest Jiaotong University Press, Chengdu, China, 1997, in Chinese.

[21] G. Li and C.-A. Tang, "A statistical meso-damage mechanical method for modeling trans-scale progressive failure process of rock," International Journal of Rock Mechanics and Mining Sciences, vol. 74, pp. 133-150, 2015.

[22] Z. Li, L. Li, B. Huang et al., "Numerical investigation on the propagation behavior of hydraulic fractures in shale reservoir based on the DIP technique," Journal of Petroleum Science and Engineering, vol. 154, pp. 302-314, 2017. 
[23] S. Wang, S. Sloan, D. Sheng, and C. Tang, "Numerical analysis of the failure process around a circular opening in rock," Computers and Geotechnics, vol. 39, pp. 8-16, 2012.

[24] S. Wang, S. Sloan, C. Tang, and W. Zhu, "A numerical investigation of the failure mechanism around tunnels in transversely isotropic rock masses," Tunnelling and Underground Space Technology, vol. 32, pp. 231-244, 2012.

[25] H. Xie, Fractals in Rock Mechanics, A A Balkema, Rotterdam, Netherlands, 1993.

[26] J. Li, Q. Du, and C. Sun, “An improved box-counting method for image fractal dimension estimation," Pattern Recognition, vol. 42, no. 11, pp. 2460-2469, 2009.

[27] C. A. Tang, "Numerical simulation of progressive rock failure and associated seismicity," International Journal of Rock Mechanics and Mining Sciences, vol. 34, no. 2, pp. pp249-261, 1997.

[28] Q. Yu, W. Zhu, C. a. Tang, and T. Yang, "Impact of rock microstructures on failure processes - numerical study based on DIP technique," Geomechanics and Engineering, vol. 7, no. 4, pp. 375-401, 2014.

[29] H. Liu, L. Zheng, Y. Zuo et al., "Study on mesoscopic damage evolution characteristics of single joint sandstone based on micro-CT image and fractal theory," Shock and Vibration, vol. 2021, Article ID 6547028, 2021.

[30] W. Weibull, "A statistical distribution function of wide applicability," Journal of Applied Mechanics, vol. 18, pp. 293297, 1951.

[31] C. A. Tang, H. Liu, P. K. K. Lee, Y. Tsui, and L. G. Tham, "Numerical studies of the influence of microstructure on rock failure in uniaxial compression - part I: effect of heterogeneity," International Journal of Rock Mechanics and Mining Sciences, vol. 37, no. 4, pp. 555-569, 1997.

[32] F. Rossi, A. D. Carlo, and P. Lugli, "Microscopic theory of quantum-transport phenomena in mesoscopic systems: a Monte Carlo approach," Physical Review Letters, vol. 80, no. 15, 1998.

[33] R. Y. Rubinstein and D. P. Kroese, Simulation and the Monte Carlo Method, 707. John Wiley and Sons, USA, 2011.

[34] H. Diao, "Rock mechanical properties and brittleness evaluation of shale reservoir," Acta Petrologica Sinica, vol. 29, no. 9, pp. 3300-3306, 2013.

[35] W. J. Whiten, "The simulation of crushing plants with models developed using multiple spline regression," Journal of the South African Institute of Mining and Metallurgy, pp. 257264, 1972.

[36] H. Xie, An Introduction to Fractal - Rock Mechanics, Science Press, Beijing, China, (in Chinese), 1996. 